\title{
Oncotype DX 21-gene test has a low recurrence score in both pure and mixed mucinous breast carcinoma
}

\author{
RUI CHEN ${ }^{1 *}$, YUN WANG $^{1 *}$, TAOLANG LI $^{1}$, JUNYUAN LV $^{1}$, \\ GUOLI FENG $^{1}$, NA TAN ${ }^{2}$, JINJING WANG ${ }^{2}$ and XIAOMING CHENG ${ }^{1}$
}

Departments of ${ }^{1}$ Thyroid and Breast Surgery and ${ }^{2}$ Pathology, The Affiliated Hospital of

Zunyi Medical University, Zunyi, Guizhou 563000, P.R. China

Received May 26, 2021; Accepted July 23, 2021

DOI: 10.3892/ol.2021.13032

\begin{abstract}
The Oncotype DX 21-gene test can be used to predict chemotherapy efficacy in patients with estrogen receptor (ER)-positive and HER2-negative breast cancer; however, the data on the 21-gene recurrence score (RS) for mucinous breast carcinoma (MBC) are limited. The present study aimed to evaluate the distribution pattern and clinical value of the 21-gene $\mathrm{RS}$ in patients with $\mathrm{MBC}$. A total of 38 pure MBC (PMBC) and 11 mixed MBC (MMBC) cases were retrospectively analyzed, and a total of 29 ER-positive and HER2-negative MBCs underwent the Oncotype DX 21-gene test. There were no statistically significant differences between the PMBCs and MMBCs in age, tumor size and molecular subtype; however, patients with MMBC showed a significantly higher incidence rate of nodal metastases compared with that in patients with PMBC (72.7 vs. 16.2\%, respectively). Following surgery, 87.8 and $59.2 \%$ of the enrolled patients received endocrine therapy and chemotherapy, respectively. With a median follow-up of 65.6 months, the 5-year disease-free survival and overall survival rates were 97.0 and $100.0 \%$, respectively. The 21-gene test revealed that the proportions of patients with MBC categorized into low ( $\mathrm{RS}<18$ ), intermediate ( $\mathrm{RS} \geq 18-30)$ and high $(\mathrm{RS} \geq 30$ ) risk groups were $51.7,44.8$ and $3.5 \%$, respectively, and there was no statistically significant difference between the PMBC and MMBC cases. Notably, among the genes in the 21-gene RS testing, the expression levels of cathepsin V,
\end{abstract}

Correspondence to: Dr Xiaoming Cheng, Department of Thyroid and Breast Surgery, The Affiliated Hospital of Zunyi Medical University, 149 Dalian Road, Zunyi, Guizhou 563000, P.R. China

E-mail:cxm1688@sina.com

Dr Jinjing Wang, Department of Pathology, The Affiliated Hospital of Zunyi Medical University, 149 Dalian Road, Zunyi, Guizhou 563000, P.R. China

E-mail: wangjinjing@163.com

${ }^{*}$ Contributed equally

Key words: mucinous breast carcinoma, 21-gene recurrence score assay, prognosis, chemotherapy, endocrine therapy progesterone receptor (PR) and CD68 were significantly higher in the PMBC group compared with that in the MMBC group. In conclusion, the current study demonstrated that patients with MBC had a favorable prognosis, and both PMBC and MMBC cases had a low- and intermediate-risk RS, which suggests that a considerable proportion of patients may be able to avoid chemotherapy. In addition, the high expression level of PR, based on the 21-gene test in PMBCs, indicated that they may have a more favorable response to endocrine therapy than MMBCs.

\section{Introduction}

Mucinous breast carcinoma (MBC) is a rare variant of breast cancer accounting for 1-6\% of all primary breast carcinomas, and is characterized by small clusters of tumor cells floating in lakes of partitioned mucin $(1,2)$. MBC has a more favorable prognosis compared with non-specific invasive ductal carcinoma (IDC), as most cases are associated with a high expression of estrogen and/or progesterone receptors $\left(\mathrm{ER} / \mathrm{PR}^{+}\right)$and a low expression of HER2 $(3,4)$. In addition, most studies have reported that MBCs have a lower frequency of axillary lymph node metastases compared with IDCs (5), which also suggests that the treatment of MBC should be different from IDC, and additional detection methods should be used to guide the treatment of MBC. According to the tumor components, MBCs are divided into two subtypes: Pure MBC (PMBC), which is defined as a tumor with a mucinous component of $>90 \%$, and mixed MBC (MMBC), which is defined as a tumor with a 51-90\% mucinous component and admixing, usually with an infiltrating ductal epithelial component $(6,7)$. A previous study reported a difference in prognosis for PMBCs and MMBCs, with a lower frequency of axillary lymph node metastases and a more favorable outcome in the former subtype (8). However, whether the treatment of these two types of breast cancer should be differentiated remains unknown.

The Oncotype DX 21-gene recurrence score (RS) assay is calculated based on the results of a reverse transcription (RT)-PCR assay of 21 prospectively selected genes in tumor tissues (9). Over the past decade, the 21-gene RS has been widely used by clinicians to assist with predicting the outcomes and guides therapeutic decisions in patients with ER-positive/HER2-negative breast cancer, and it has become the only genomic test recommended by National 
Comprehensive Cancer Network guidelines (10,11). Further validation studies also confirmed its ability to predict the benefit from chemotherapy (CT) both in node-negative and node-positive cases $(12,13)$. Notably, the majority of MBCs have favorable features, including being ER-positive and HER2-negative and having a lower incidence rate of nodal metastasis, which matches the criteria of the 21-gene genomic test (14), thereby suggesting that a considerable number of patients with MBC may avoid unnecessary CT after the Oncotype DX 21-gene test. However, at present, data on the $\mathrm{RS}$ of MBC remains limited, due to its relative rarity, and it remains unknown whether the accuracy, practicability and effectiveness of the 21-gene RS test in guiding the treatment of IDC is also suitable for MBC due to tumor heterogeneity (15).

The present study retrospectively investigated the clinicopathological features and treatment patterns of 49 cases of $\mathrm{MBC}$, and the Oncotype DX 21-gene RS test was performed in 29 cases of MBC. We hypothesized that the results of the 21-gene test could be used to guide the treatment in patients with MBC. Furthermore, the clinicopathological features and the 21-gene RSs were compared between patients with PMBC and those with MMBC. In addition, the individual gene expression from the 21-gene test was also analyzed between the PMBC and MMBC groups.

\section{Materials and methods}

Patients and follow-up. In total, 50 women who were diagnosed with MBC and treated at the Department of Thyroid and Breast Surgery, Affiliated Hospital of Zunyi Medical University (Guizhou, China) between February 2010 and February 2021, were retrospectively included. During this period, a total of 3,081 patients were diagnosed with breast cancer, and MBC accounted for $1.59 \%$. The main inclusion criteria were as follows: Female, without distant metastasis at first diagnosis and confirmed to be MBC by the Pathology Department of The Affiliated Hospital of Zunyi Medical University. The main exclusion criteria were as follows: Male, bilateral cancer, presence of distant metastasis and unavailability of tissue samples. A total of 49 patients were included in this study according to the aforementioned criteria, and 1 patient was excluded due to the inability to obtain tissue samples. All available clinicopathological data, including age, menstrual status, tumor size, lymph node status, TNM stage, immunohistochemistry (IHC) results and treatment were collected from the medical records. The patients received all therapeutic procedures, such as surgery, adjuvant CT, irradiation and hormonotherapy at the same institution (Table I).

The time to follow-up was from the date of surgery to the date of recent follow-up. Patient follow-up was accomplished by specialized staff at the Department of Thyroid and Breast Surgery, Affiliated Hospital of Zunyi Medical University, and routine correspondence and telephone calls were used for follow-up. The follow-ups were performed every 3 months during the first 2 years, every 6 months during the next 3 years, then once a year thereafter. Overall survival (OS) time was calculated from the date of surgery to the occurrence death of any cause. Disease-free survival (DFS) time was estimated from the date of surgery until the date of first proven recurrence, including local/regional recurrence and distant metastasis at any site. The last follow-up was conducted in April 2021. The current study was approved by the Ethical Committee of The Affiliated Hospital of Zunyi Medical University. All procedures were in accordance with the 1964 Declaration of Helsinki and its later amendments. Written informed consent was provided by all the patients, and all tissue samples used were from paraffin embedded tissues following surgery. The tumor tissue was fixed with $10 \%$ neutral buffered formalin at room temperature overnight, and the $4-\mu \mathrm{m}$ thick tissue sections were used for pathological evaluation.

Hematoxylin \& eosin $(H \& E)$ staining. H\&E-stained slides of the MBCs were reviewed according to the 2012 World Health Organization classification criteria (16). The histological sections were stained with hematoxylin for 8-10 min and eosin for 4-5 sec at room temperature, then the stained sections were observed under a light microscope (magnifications $\mathrm{x} 40$ and $\mathrm{x} 100$ ). PMBCs were defined as having a mucinous component of $>90 \%$ and MMBC was defined with a 51-90\% mucinous component. In addition, hypocellular MBC (type A) and hypercellular MBC (type B) were also determined based on cell cluster density (17).

IHC analyses. ER, PR, HER-2 status and the Ki-67 index were evaluated using IHC. Briefly, the $4-\mu \mathrm{m}$ thick tissue sections were incubated with the immunohistochemical antigen repair buffer (cat. no. MVS-0099; Beijing Strong Biotechnologies, Inc.) for 20 min after dewaxing in xylene for $60 \mathrm{~min}$ and rehydrated in a descending alcohol series $(100,95$ and $75 \%)$ at room temperature. Subsequently, the tissue sections were blocked using an endogenous biotin blocking kit (cat. no. BLK-0002; Beijing Strong Biotechnologies, Inc.) for $10 \mathrm{~min}$ at room temperature. After washing with PBS, the tissue sections were incubated for 32 min at $42^{\circ} \mathrm{C}$ with primary antibodies targeted against ER (cat. no. kit-0012; clone SP1; 1:100; rabbit monoclonal), PR (cat. no. kit-0013; clone SP2; 1:100; rabbit monoclonal), HER2 (cat. no. Kit-0043; clone MXR001; 1:100; rabbit monoclonal) and Ki-67 (cat. no. RMA-0731; clone MXR002; 1:100; rabbit monoclonal) (all from Beijing Strong Biotechnologies, Inc.). After washing with PBS, the tissue sections were processed with a Maxvision ${ }^{\mathrm{TM}} \mathrm{HRP}$ kit (cat. no. kit-5004; Beijing Strong Biotechnologies, Inc.). The IHC results were judged by experienced pathologists using a light microscope (magnification, $x 40$ and $x 100$ ), and the ER and PR were regarded as positive if $>1 \%$ of nuclei were stained (18). With respect to $\mathrm{Ki}-67$, a range of 500-1,000 cells were counted to calculate the percentage of positive tumor cell nuclei, including hot spot areas (19). The molecular subtype was classified according to the 2013 St. Gallen expert panel consensus (20). All histological and IHC tumor slides were evaluated independently by two pathologists.

Fluorescence in situ hybridization (FISH). HER2 status was considered to be positive if $>10 \%$ of the tumor cells showed a score of $3+$ from IHC or showed a $>2.2$-fold increase in FISH using a HER2 DNA Probe kit (cat. no. 2J01-30; Abbott Molecular Inc.) (21). Briefly, after the samples were deparaffinized, dehydrated and air-dried, the tissue sections were handled with pre-treatment solution at $80^{\circ} \mathrm{C}$ for $30 \mathrm{~min}$. 
Table I. Detailed IHC and adjuvant treatment information of the enrolled patients.

Case ID ER status PR status HER2 status $^{\mathrm{a}}$ Ki67,\% Molecular subtype Chemotherapy Endocrine therapy Irradiation

\begin{tabular}{|c|c|c|c|c|c|c|c|c|}
\hline MMBC1 & Positive & Negative & Negative & 30 & B & Yes & Yes & Yes \\
\hline MMBC2 & Positive & Negative & Negative & 2 & B & Yes & Yes & No \\
\hline МMBC3 & Positive & Negative & Negative & 30 & B & Yes & Yes & Yes \\
\hline MMBC4 & Positive & Positive & Negative & 10 & A & No & Yes & No \\
\hline MMBC5 & Positive & Positive & Negative & 10 & A & Yes & Yes & No \\
\hline MMBC6 & Positive & Positive & Negative & 10 & A & Yes & Yes & No \\
\hline MMBC7 & Positive & Positive & Negative & 5 & A & Yes & Yes & No \\
\hline MMBC8 & Positive & Positive & Positive & 20 & B/HER2 & Yes & Yes & No \\
\hline ММВС9 & Positive & Negative & Negative & 20 & B & No & Yes & No \\
\hline MMBC10 & Positive & Positive & Positive & 10 & B/HER2 & Yes & Yes & No \\
\hline MMBC11 & Positive & Positive & Positive & 20 & B/HER2 & Yes & Yes & Yes \\
\hline PMBC1 & Positive & Positive & Negative & 5 & A & No & Yes & No \\
\hline PMBC2 & Positive & Positive & Negative & 10 & A & Yes & Yes & No \\
\hline PMBC3 & Positive & Positive & Negative & 15 & $\mathrm{~B}$ & Yes & Yes & No \\
\hline PMBC4 & Positive & Positive & Negative & 20 & B & Yes & Yes & No \\
\hline PMBC5 & Positive & Positive & Negative & 10 & A & No & Yes & No \\
\hline PMBC6 & Positive & Positive & Negative & 20 & B & Yes & Yes & Yes \\
\hline PMBC7 & Positive & Positive & Negative & 10 & A & No & Yes & No \\
\hline PMBC8 & Positive & Positive & Negative & 15 & A & No & Yes & No \\
\hline PMBC9 & Positive & Positive & Negative & 3 & B & Yes & Yes & No \\
\hline PMBC 10 & Positive & Positive & Negative & 20 & B & No & No & No \\
\hline PMBC11 & Positive & Positive & Negative & 10 & B & No & Yes & No \\
\hline PMBC12 & Positive & Positive & Negative & 10 & A & No & Yes & No \\
\hline PMBC 13 & Negative & Negative & Negative & 80 & TNBC & No & No & No \\
\hline PMBC14 & Positive & Positive & Negative & 20 & B & Yes & Yes & No \\
\hline PMBC15 & Positive & Positive & Negative & 10 & A & Yes & Yes & No \\
\hline PMBC 16 & Positive & Positive & Negative & 5 & A & No & Yes & No \\
\hline PMBC17 & Positive & Negative & Negative & 5 & B & Yes & Yes & No \\
\hline PMBC 18 & Positive & Positive & Negative & 60 & $\mathrm{~B}$ & Yes & Yes & Yes \\
\hline PMBC19 & Negative & Negative & Positive & 20 & HER2 & Yes & No & No \\
\hline PMBC20 & Negative & Negative & Positive & 40 & HER2 & Yes & No & Yes \\
\hline PMBC21 & Positive & Positive & Negative & 15 & A & Yes & Yes & No \\
\hline PMBC 22 & Positive & Negative & Negative & 10 & B & No & Yes & No \\
\hline PMBC23 & Positive & Positive & Negative & 5 & A & No & Yes & Yes \\
\hline РMBC24 & Positive & Positive & Negative & 10 & A & Yes & Yes & No \\
\hline PMBC 25 & Positive & Positive & Negative & 10 & A & No & Yes & No \\
\hline PMBC26 & Positive & Positive & Negative & 10 & A & Yes & Yes & Yes \\
\hline РMBC27 & Positive & Positive & Negative & 5 & A & No & Yes & No \\
\hline PMBC28 & Positive & Positive & Negative & 10 & A & No & Yes & No \\
\hline РMBC29 & Positive & Positive & Negative & 20 & B & No & Yes & No \\
\hline РMBC 30 & Positive & Positive & Negative & 10 & A & No & Yes & Yes \\
\hline PMBC31 & Positive & Positive & Negative & 50 & B & Yes & Yes & No \\
\hline PMBC32 & Positive & Negative & Negative & 20 & B & Yes & Yes & Yes \\
\hline PMBC 33 & Positive & Positive & Negative & 40 & B & Yes & Yes & Yes \\
\hline РMBC34 & Positive & Positive & Negative & 10 & A & Yes & Yes & No \\
\hline PMBC35 & Positive & Positive & Negative & 1 & A & No & Yes & No \\
\hline PMBC36 & Positive & Positive & Negative & 10 & A & Yes & Yes & No \\
\hline РMBC37 & Positive & Positive & Negative & 10 & A & No & Yes & No \\
\hline PMBC38 & Negative & Negative & Negative & 5 & TNBC & No & No & No \\
\hline
\end{tabular}

${ }^{a}$ From IHC and FISH. PMBC, pure mucinous breast carcinoma; MMBC, mixed mucinous breast carcinoma; IHC, immunohistochemistry; FISH, fluorescence in situ hybridization; A, luminal A subtype; B, luminal B subtype; HER2, human epidermal growth factor receptor 2 subtype; TN, triple-negative subtype. 
Then, the sections were immersed in protease solution at $37^{\circ} \mathrm{C}$ for $34 \mathrm{~min}$, followed by immersion in wash buffer (70, 80 and $100 \%$ ethanol). Subsequently, the tissue sections were incubated with the probe mixture [10 $\mu$ l HER2 probe (226 kb; $10 \mathrm{ng} / \mu \mathrm{l})$ and $10 \mu \mathrm{l} \mathrm{CEP17} \mathrm{probe}(9 \mathrm{~kb} ; 20 \mathrm{ng} / \mu \mathrm{l})]$ at $74^{\circ} \mathrm{C}$ for $5 \mathrm{~min}$, then the cover slip was sealed with Fixogum rubber cement (cat. no. 12101ES62; Marabu GmbH and Co. $\mathrm{KG}$ ) for $10 \mathrm{~min}$ at room temperature, and the samples were subsequently incubated overnight at $37^{\circ} \mathrm{C}$. Next, the samples were washed with post-hybridization wash buffer at room temperature for $15 \mathrm{~min}$. After air-drying, $10 \mu \mathrm{l}$ DAPI (cat. no. 30-804840; Abbott Molecular Inc.) was added to the target area and a cover glass was added and the samples were incubated at $-20^{\circ} \mathrm{C}$ for $10 \mathrm{~min}$. After the slides were stored in the dark and left at room temperature, the FISH results were judged by experienced pathologists using a fluorescence microscope (magnification, $\mathrm{x} 40$ and $\mathrm{x} 100$ ).

Testing using the 21-gene RS assay. The Oncotype DX 21-gene test was performed by AmoyDx Diagnostics Co., Ltd. Briefly, the H\&E-stained slides were reviewed by pathologists to ensure that the paraffin section contained sufficient tumor tissue. RNA was then extracted from the unstained breast tumor formalin fixed paraffin-embedded (FFPE) sections using a RNeasy FFPE RNA kit (cat. no. 172348; AmoyDx Diagnostics Co., Ltd), and the concentration was measured after verifying the absence of DNA contamination. Gene-specific RT was performed at $65^{\circ} \mathrm{C}$ for $5 \mathrm{~min}$ and $37^{\circ} \mathrm{C}$ for $60 \mathrm{~min}$ using the PrimeScript RT Master Mix kit (Takara Biotechnology, Co., Ltd.). Subsequently, standardized quantitative PCR was performed using Premix Ex Taq ${ }^{\mathrm{TM}}$ (Takara Bio, Inc.) in 384-well plates and an Applied Biosystems Real-Time PCR system (Applied Biosystems; Thermo Fisher Scientific, Inc.) and the following thermocycling conditions were used: Initial denaturation at $95^{\circ} \mathrm{C}$ for $10 \mathrm{~min}$, $95^{\circ} \mathrm{C}$ for $20 \mathrm{sec}$ and $60^{\circ} \mathrm{C}$ for $45 \mathrm{sec}$ (for 40 cycles). The 16 genes examined comprised of five proliferation-related genes [Ki-67, aurora kinase A (AURKA), baculoviral IAP repeat containing 5 (BIRC5), cyclin B1 (CCNB1) and MYB proto-oncogene like 2 (MYBL2)], two metastasis-related genes [MMP11 and cathepsin V (CTSV)], two HER2-related genes [growth factor receptor bound protein 7 (GRB7) and HER2], four hormone-related genes [ER, PR, BCL2 and signal peptide CUB domain and EGF like domain containing 2 (SCUBE2)] and three independent genes [glutathione S-transferase mu 1 (GSTM1), BAG cochaperone 1 (BAG1) and CD68], which were normalized according to five reference genes (ACTB, GAPDH, RPLP0, GUSB and TFRC). Therefore, 16 cancer-related genes in 21 genes can be used to predict the outcome of patients. The expression of the genes was confirmed in triplicate, and the relative gene expression was calculated using the $2^{-\Delta \Delta C q}$ method (22), and the RS was calculated based on the Oncotype DX formula (10). According to the RS results, patients were categorized into low-risk ( $\mathrm{RS}<18)$, intermediate-risk $(\mathrm{RS} \geq 18-30)$ and high-risk $(\mathrm{RS} \geq 30)$ groups (23). For further analysis, the individual gene expression of the 16-cancer genes was measured, and the distribution of the 16-cancer gene expression in $\mathrm{PMBC}$ and $\mathrm{MMBC}$ cases was analyzed.

Statistical analysis. The clinicopathological characteristics were presented as patient number and percentage and the other data was expressed as the mean \pm standard deviation and range. The $\chi^{2}$ test or Fisher's exact test were used to evaluate associations between PMBC and MMBC, while the Kruskal-Wallis test was used to compare quantitative characteristics. Logistic regression was used in multivariate analyses to identify risk factors impacting lymph node metastasis. The Kaplan-Meier estimation (log-rank test) was used to assess DFS and OS rate, and the Cox proportional hazard model was used to analyze the prognostic factors of patients with MBC. The Mann-Whitney test was used to assess the distribution of the 21-gene RS in the different subgroups, and to compare the expression levels of the 16 cancer genes between subgroups. $\mathrm{P}<0.05$ was considered to indicate a statistically significant difference. SPSS version 22.0 software (IBM Corp.) was used for all the statistical analyses.

\section{Results}

Patients and baseline clinicopathological features. In total, 49 cases diagnosed as MBC (38 PMBCs and 11 MMBCs) were included in this analysis and the pathological changes of various typical MBCs are shown in Fig. 1. The median age at diagnosis was $52.3 \pm 12.8$ years (range, 33-87 years), and $44.9 \%$ of these patients were postmenopausal. The median tumor size was $3.2 \pm 1.8 \mathrm{~cm}$ (range, $1.0-8.5 \mathrm{~cm}$ ) at diagnosis, and $29.2 \%$ of cases had axillary lymph node involvement. According to IHC and FISH results, 45 (91.8\%) and 38 (77.6\%) patients with MBC were ER and PR positive, respectively. In $5(10.2 \%)$ of the patients with MBC, HER2 positivity was detected, while $34.7 \%$ of all patients had $\geq 20 \% \mathrm{Ki}-67$ expression. For the molecular subtype, $49.0 \%(n=24)$ were classified as luminal A, 42.8\% $(n=21)$ as luminal B, 4.1\% $(n=2)$ as HER2-rich and $4.1 \%(n=2)$ as triple negative. The detailed clinicopathological characteristics of the patients are shown in Table II.

The mean age at diagnosis in patients with PMBC and MMBC was $51.5 \pm 13.4$ years (range, 33-87 years) and $54.9 \pm 10.8$ years (range, 33-78 years), respectively $(\mathrm{P}=0.25)$, and the mean tumor size in PMBCs and MMBCs was $3.19 \pm 1.8 \mathrm{~cm}$ (range, $1.2-8.5 \mathrm{~cm}$ ) and $3.17 \pm 1.6 \mathrm{~cm}$ (range, $1.0-5.0 \mathrm{~cm})$, respectively $(\mathrm{P}=0.914)$. The data showed no significant differences between PMBCs and MMBCs with respect to TNM stage $(\mathrm{P}=0.261)$, molecular subtype $(\mathrm{P}=0.17)$, status of ER $(\mathrm{P}=0.562)$, status of $\mathrm{PR}(\mathrm{P}=0.398)$ and $\mathrm{Ki}-67$ expression $(\mathrm{P}=0.395)$. However, a significantly higher incidence rate of axillary lymph node involvement was observed in MMBCs comparison with that in PMBCs (72.7 vs. $16.2 \%$, respectively; $\mathrm{P}=0.001)$. The clinicopathological characteristics of the PMBCs and MMBCs are detailed in Table III. Similarly, the results of multivariate analysis demonstrated that the only high-risk factor of lymph node metastasis in patients with $\mathrm{MBC}$ was the pathological subtype $(\mathrm{P}=0.018$; Table IV). Furthermore, the status of HER2 had a marginal $\mathrm{P}$-value $(\mathrm{P}=0.068)$ in the two groups, and a higher incidence rate was observed in MMBCs compared with that in PMBCs (27.3 vs. $5.3 \%)$.

Treatment and prognosis in patients with $M B C$. A total of $98.0 \%$ of the patients with MBC in the present study underwent radical mastectomies (1 patient refused surgery), and the 
A

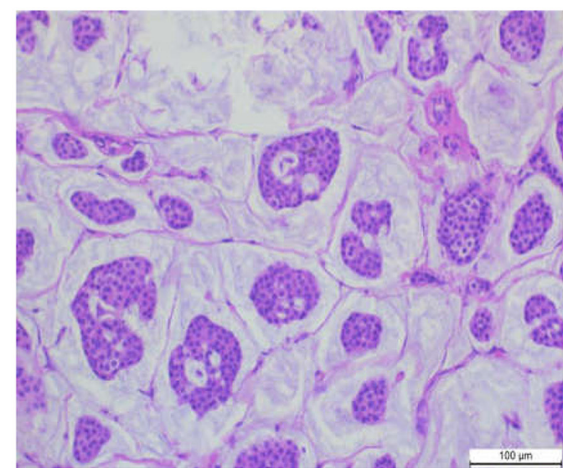

C

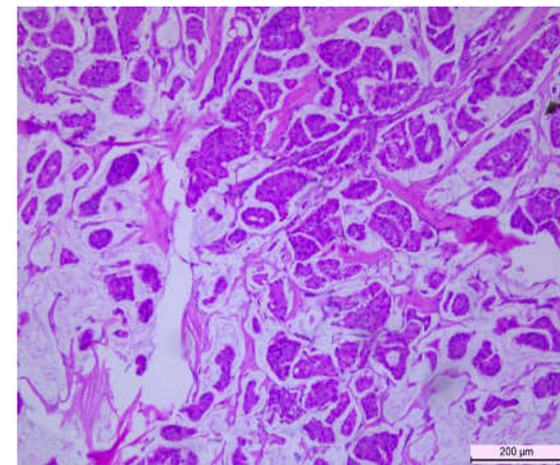

E

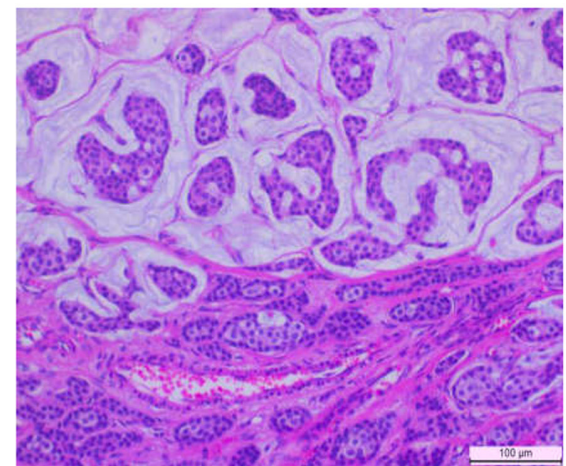

B

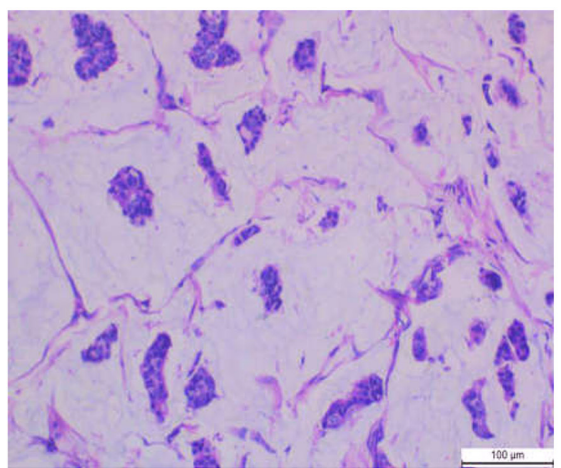

D

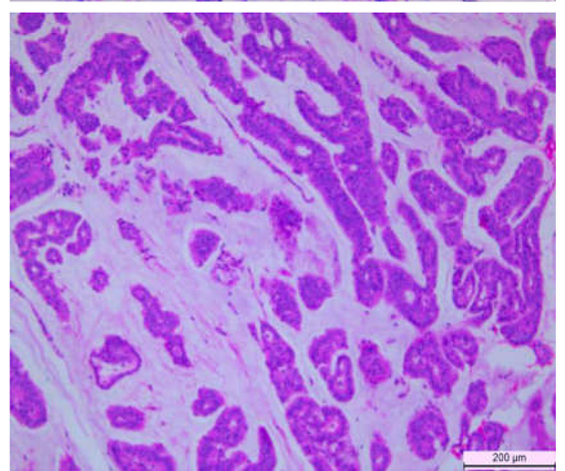

F

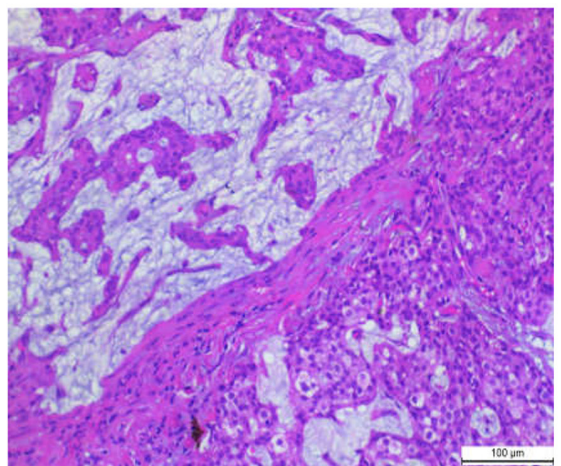

Figure 1. Histological features of different subtypes of breast mucinous carcinoma. (A and B) Type A (Paucicellular) variant. (C and D) Type B (hypercellular) variant. (E and F) mixed mucinous carcinoma variant.

first-line treatment selections following surgery in the $\mathrm{MBC}$ cases with different subtypes are presented in Fig. 2A. Overall, $8.2 \%(n=4), 36.7 \%(n=18)$ and $51 \%(n=25)$ of enrolled patients received $\mathrm{CT}$, endocrine therapy (ET) and CT followed by ET as first-line treatment according to the molecular subtypes, respectively. The detailed adjuvant treatment of the MBC cases with various molecular subtypes are shown in Table I. Of all the patients with HER2 expression amplification, only 1 patient (20\%) received trastuzumab therapy. In the PMBC and MMBC cases, the proportion of those receiving $\mathrm{CT}$ was 55.3 and $72.7 \%$, respectively, and there was no statistical significance ( $\mathrm{P}=0.102$; data not shown).

The mean follow-up time for patients with MBC was 65.6 months (range, 2-125 months), and 2 patients were lost during this time. As shown in Fig. 2B and C, the 5-year DFS and 5-year OS rates for MBC was 97 and 100\%, respectively, and this result was not statistically significant between PMBCs and MMBCs (log-rank test; $\mathrm{P}=0.457$ ).

During the study period, distant metastases were found in 5 patients with high TNM stage ( 3 cases with stage III and 2 cases with stage II), and 2 of these patients died from lung metastases (both HER2 expression positive). In addition, 1 patient with PMBC with no recurrence died of a cardiovascular accident. The causes of treatment failure in MBCs cases are presented in Table V. In addition, Cox multivariate analysis did not identify any statistically significant factors associated with the prognosis of patients with MBC (Table VI).

Comparison of Oncotype DX 21-gene RS and individual gene expression between the PMBC and MMBC groups. In the present study, 29 of the 42 enrolled ER-positive and HER2-negative MBC cases underwent Oncotype DX 21-gene testing (the sample quality of 13 cases did not meet the test) and the results were evaluable, which included 21 PMBCs and 8 MMBCs. According to the criteria of 21-gene test RS stratification, $51.7 \%$ patients $(15 / 29)$ were in the low-risk group $(\mathrm{RS}<18)$ with a mean RS of $10.5 \pm 5.6,44.8 \%$ patients $(13 / 29)$ were in the intermediate-risk group (RS $\geq 18-30)$ with a mean RS of $22.3 \pm 5.2$, and $3.5 \%$ patients $(1 / 29)$ were in the high-risk group $(\mathrm{RS} \geq 30)$ ( $\mathrm{RS}, 35.7)$. The proportions of low-, intermediate- and high-risk RS were 42.9, 52.3 and $4.8 \%$, 
Table II. Clinicopathological features of patients with mucinous breast carcinoma $(n=49)$.

\begin{tabular}{|c|c|}
\hline Parameters & Number $(\%)$ \\
\hline \multicolumn{2}{|l|}{ Age, years } \\
\hline$\leq 50$ & $26(53.1)$ \\
\hline$\geq 50$ & $23(46.9)$ \\
\hline \multicolumn{2}{|l|}{ Menstruation } \\
\hline Premenopausal & $27(55.1)$ \\
\hline Postmenopausal & $22(44.9)$ \\
\hline \multicolumn{2}{|l|}{ Tumor size, $\mathrm{pT}^{\mathrm{a}}$} \\
\hline $\mathrm{T} 1$ & $18(37.5)$ \\
\hline $\mathrm{T} 2$ & $18(37.5)$ \\
\hline $\mathrm{T} 3$ & $12(25.0)$ \\
\hline \multicolumn{2}{|l|}{ Nodal status, $\mathrm{pN}^{\mathrm{a}}$} \\
\hline N0 & $34(70.8)$ \\
\hline N1 & 7 (14.6) \\
\hline N2 & $6(12.5)$ \\
\hline N3 & $1(2.1)$ \\
\hline \multicolumn{2}{|l|}{ TNM stage ${ }^{a}$} \\
\hline I & $13(27.1)$ \\
\hline II & $26(54.2)$ \\
\hline III & $9(18.7)$ \\
\hline \multicolumn{2}{|l|}{ Subtype } \\
\hline PMBC & $38(77.6)$ \\
\hline MMBC & $11(22.4)$ \\
\hline \multicolumn{2}{|l|}{ ER status } \\
\hline Positive & $45(91.8)$ \\
\hline Negative & $4(8.2)$ \\
\hline \multicolumn{2}{|l|}{ PR status } \\
\hline Positive & 38 (77.6) \\
\hline Negative & $11(22.4)$ \\
\hline \multicolumn{2}{|l|}{ HER2 status } \\
\hline Positive & $5(10.2)$ \\
\hline Negative & $44(89.8)$ \\
\hline \multicolumn{2}{|l|}{ Ki67, \% } \\
\hline$<20$ & $32(65.3)$ \\
\hline$\geq 20$ & $17(34.7)$ \\
\hline \multicolumn{2}{|l|}{ Molecular subtype ${ }^{b}$} \\
\hline Luminal A & $24(49.0)$ \\
\hline Luminal $\mathrm{B}^{\mathrm{c}}$ & $21(42.8)$ \\
\hline HER2 & $2(4.1)$ \\
\hline Triple negative & $2(4.1)$ \\
\hline
\end{tabular}

${ }^{a}$ There was one patient did not receive surgery. ${ }^{\mathrm{b}}$ The Molecular subtype was defined based on the 2013 St. Gallen consensus. ${ }^{\text {CThis }}$ includes 11 patients who are ER-positive and HER2-negative and 3 patients who are ER-positive and HER2-positive. ER, estrogen receptor; $\mathrm{PR}$, progesterone receptor; HER2, human epidermal growth factor receptor 2; $\mathrm{PMBC}$, pure mucinous breast carcinoma; $\mathrm{MMBC}$, mix mucinous breast carcinoma.

respectively, among $\mathrm{PMBCs}$, and 50.0, 50.0 and $0 \%$ in the MMBCs $(\mathrm{P}=0.91$; Fig. $3 \mathrm{~A})$. The mean 21-gene $\mathrm{RS}$ in the
PMBC and MMBC groups was 18.0 and 13.0, respectively $(\mathrm{P}=0.151$; Fig. 3B). Notably, based on the traditional RS treatment recommendation, $37.9 \%$ of patients with $\mathrm{MBC}$ in the present study could avoid CT (Fig. S1).

The individual gene expression of the 16 cancer genes from the 21-gene test between the PMBC and MMBC groups was analyzed. The histograms of the distribution of cancer gene expression in the different histological-type subgroups are presented in Fig. 3C. In general, the expression levels of the genes from the proliferation and HER2 groups did not differ significantly between the PMBC and MMBC cases. In the metastasis group, the expression level of CTSV $(\mathrm{P}=0.005)$ was significantly higher in the PMBC group compared with that in the MMBC group. In the ER group, the expression level of $\mathrm{PR}(\mathrm{P}=0.018)$ was significantly higher in the $\mathrm{PMBC}$ group compared with that in the MMBC group, and the expression level of ESR1 had a marginal $\mathrm{P}$-value $(\mathrm{P}=0.053)$. Furthermore, in the independent group, the expression level of CD68 was higher in the PMBC group $(\mathrm{P}=0.003)$, while the expression levels of GSTM1 and BAG1 did not differ significantly between groups. The detailed expression of the 16 cancer genes between the PMBC and MMBC groups are shown in Table VII.

\section{Discussion}

$\mathrm{MBC}$ is a rare histological type of primary breast cancer and a previous epidemiological survey reported that the incidence rate of MBC in Caucasians was lower compared with that in Africans (24). Prior studies indicated that the majority of MBC cases were ER-positive, HER2-negative tumors without node metastasis, which suggested that the treatment of MBC should be different from IDC (14). Therefore, it is necessary to divide patients into different subgroups according to the recurrence risk and it can be used to choose more reasonable adjuvant therapy. The 21-gene RS has been proved to assist clinicians with therapeutic decisions; however, data on the RS of $\mathrm{MBC}$ remains limited and to the best of our knowledge, this topic has not been addressed in large studies. The present study assessed the clinicopathological features, treatment and prognosis of patients with MBC. More importantly, it evaluated the distribution pattern and clinical value of the 21-gene RS in patients with MBC. To the best of our knowledge, the current study represents the first study focused on comparing the 21-gene RS and individual gene expression for patients with PMBC and those with MMBC.

In the current study, from the 3,081 patients with invasive breast cancer, $49(1.59 \%)$ had $\mathrm{MBC}$ and the incidence rate was similar to that of other studies $(1,2,25)$. The present results demonstrated that postmenopausal women accounted for $44.9 \%$ of all MBCs, and $91.8 \%$ (45/49) and 77.6\% (38/49) MBC cases were ER- and PR-positive, respectively, which were consistent with previous findings $(3,4)$. In addition, $29.2 \%$ of MBCs had axillary lymph node metastases, which was higher than the incidence rate of axillary metastases, ranging from $3-26 \%$, reported in the literature $(1,2,4,5)$. This may be because $22.4 \%$ of the cases (11/49) in the current study were MMBCs. Next, the present study compared the clinicopathological characteristics of patients with PMBC and those with MMBC. There were no significant differences between 
Table III. Comparison of clinicopathological characteristics in patients with PMBC and MMBC.

\begin{tabular}{|c|c|c|c|}
\hline Characteristic & PMBC & MMBC & P-value \\
\hline Mean age \pm SD (range), years & $51.5 \pm 13.4(33-87)$ & $54.9 \pm 10.8(39-78)$ & 0.25 \\
\hline Mean tumor size $\pm \mathrm{SD}$ (range), $\mathrm{cm}$ & $3.19 \pm 1.8(1.2-8.5)$ & $3.17 \pm 1.6(1.0-5.0)$ & 0.914 \\
\hline Nodal status, $\mathrm{pN}^{\mathrm{a}}$ & & & 0.001 \\
\hline No & 31 & 3 & \\
\hline N1-3 & 6 & 8 & \\
\hline TNM stage ${ }^{a}$ & & & 0.261 \\
\hline I & 11 & 2 & \\
\hline II & 21 & 5 & \\
\hline III & 5 & 4 & \\
\hline ER status & & & 0.562 \\
\hline Positive & 34 & 11 & \\
\hline Negative & 4 & 0 & \\
\hline PR status & & & 0.398 \\
\hline Positive & 31 & 7 & \\
\hline Negative & 7 & 4 & \\
\hline HER2 status & & & 0.068 \\
\hline Positive & 2 & 3 & \\
\hline Negative & 36 & 8 & \\
\hline Ki67,\% & & & 0.395 \\
\hline$<20$ & 26 & 6 & \\
\hline$\geq 20$ & 12 & 5 & \\
\hline Molecular subtype ${ }^{b}$ & & & 0.17 \\
\hline Luminal A & 21 & 4 & \\
\hline Luminal B & 14 & 7 & \\
\hline HER2 & 2 & 0 & \\
\hline Triple negative & 2 & 0 & \\
\hline
\end{tabular}

${ }^{a}$ There was one patient did not receive surgery. ${ }^{b}$ The Molecular subtype was defined based on the 2013 St. Gallen consensus. ER, estrogen receptor; PR, progesterone receptor; HER2, human epidermal growth factor receptor 2; PMBC, pure mucinous breast carcinoma; MMBC, mix mucinous breast carcinoma.

PMBCs and MMBCs with respect to age, tumor size, TNM stage, ER status, PR status and Ki-67 expression. However, patients with MMBC showed a significantly higher incidence rate of axillary nodal metastases compared with those with PMBC (72.7 vs. 16.2\%), which was consistent with previous studies $(8,26)$. Notably, a higher incidence rate of HER2 positivity was observed in MMBCs in comparison with PMBCs (27.3 vs. 5.3\%), and this phenomenon has been confirmed by other study (27).

The present study also assessed the treatment and prognosis in PMBC and MMBC cases. According to the clinical stage and molecular subtype, $55.3 \%$ of PMBCs and $72.7 \%$ of $\mathrm{PMBC}$ received $\mathrm{CT}$, while the proportion of $\mathrm{PMBC}$ and $\mathrm{MMBC}$ cases receiving ET was 84.2 and $100.0 \%$, respectively. With a mean follow-up of 65.6 months (range, 2-125 months), it was demonstrated that patients with MBC had excellent 5-year DFS (97.0\%) and OS (100.0\%) rates, which was similar to findings of other studies $(3,28,29)$. However, the difference in the 5-year DFS and OS rates between PMBCs and MMBCs were statistically insignificant, which was not consistent with previous studies $(8,17)$. This phenomenon could be explained by the relatively short follow-up time and small number of patients with metastasis and those that died.

In the present study, Oncotype DX 21-gene testing was performed in 29 ER-positive/HER2-negative patients with $\mathrm{MBC}$, including $21 \mathrm{PMBC}$ and $8 \mathrm{MMBCs}$. The results indicated that $51.7 \%$ of MBC cases were in the low-risk group, with a mean $\mathrm{RS}$ of $10.5 \pm 5.6$, although 4 patients $(26.7 \%)$ had lymph node metastases. The intermediate-risk group included 13 patients with $\mathrm{MBC}$, which had a mean RS of $22.3 \pm 5.2$, and 5 patients $(28.5 \%)$ in this group had lymph node metastases. In addition, only 1 node-negative cases was classified into the high risk group, with a mean RS of 35.7. These results showed a lower proportion of patients with low-risk and a higher proportion of patients with intermediate-risk compared with that in the study by Turashvili et al (29), which may be due to the fact that the patients included in the current study have more high-risk clinical factors. Based on the traditional RS treatment recommendation, $37.9 \%$ of patients with $\mathrm{MBC}$ in the 
Table IV. Logistic regression analysis of factors predicting lymph node metastasis.

\begin{tabular}{lrrrrrr}
\hline & & & & & \multicolumn{2}{c}{$95 \%$ CI } \\
\cline { 5 - 7 } Parameters & \multicolumn{1}{c}{ B } & \multicolumn{1}{c}{ S.E } & Wald & P-value & Lower & Upper \\
\hline Age $(<50$ vs. $>50$ years) & -1.274 & 0.928 & 1.885 & 0.170 & 0.045 & 1.724 \\
Tumor size $(<2$ vs. $>2$ cm) & 0.791 & 0.858 & 0.849 & 0.375 & 0.410 & 11.853 \\
ER (positive vs. negative) & 19.138 & 17425.283 & 0.000 & 0.999 & N/A & N/A \\
PR (positive vs. negative) & 0.056 & 1.116 & 0.030 & 0.960 & 0.119 & 9.419 \\
HER2 (positive vs. negative) & 20.274 & 17425.283 & 0.000 & 0.999 & N/A & N/A \\
Ki67 (<20 vs. $>20 \%)$ & 0.809 & 0.938 & 0.743 & 0.389 & 0.357 & 14.116 \\
Subgroup (PMBC vs. MMBC) & 2.629 & 1.116 & 2.527 & 0.018 & 1.556 & 123.560 \\
Constant & -21.074 & 17425.283 & 0.000 & 0.999 & & \\
\hline
\end{tabular}

ER, estrogen receptor; PR, progesterone receptor; HER2, human epidermal growth factor receptor 2; B, regression coefficient; S.E, standard error; Wald, $\chi^{2}$ value; N/A, not available; CI, confidence intervals.

Table V. Disease recurrence and survival profile of the enrolled patients.

\begin{tabular}{lccccc}
\hline Recurrence/metastasis sites & Pathological subtype & Molecular subtype & Stage & TTR $^{\text {a }}$, month & Outcome \\
\hline Chest wall and lung & MMBC & B/HER2 & T3N2M0 & 50 & Death \\
Lung & PMBC & B & T2N0M0 & 76 & Survival \\
Bone and lung & MMBC & B/HER2 & T3N1M0 & 79 & Death \\
Bone & PMBC & A & T3N2M0 & 72 & Survival \\
Bone & PMBC & A & T2N0M0 & 58 & Survival
\end{tabular}

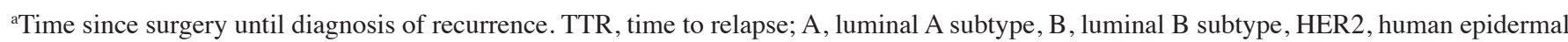
growth factor receptor 2 subtype; PMBC, pure mucinous breast carcinoma; MMBC, mix mucinous breast carcinoma.

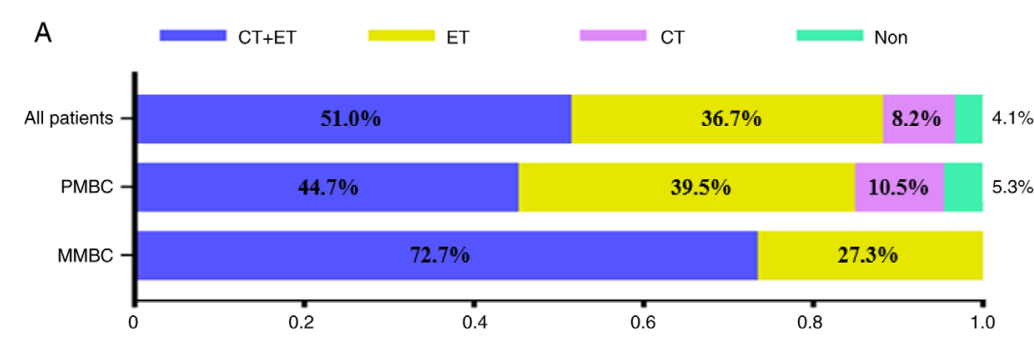

\begin{tabular}{|c|c|c|c|c|}
\hline & CT+ET & ET & CT & Non \\
\hline All patients & 25 & 18 & 4 & 2 \\
\hline PMBC & 17 & 15 & 4 & 2 \\
\hline MMBC & 8 & 3 & & \\
\hline
\end{tabular}
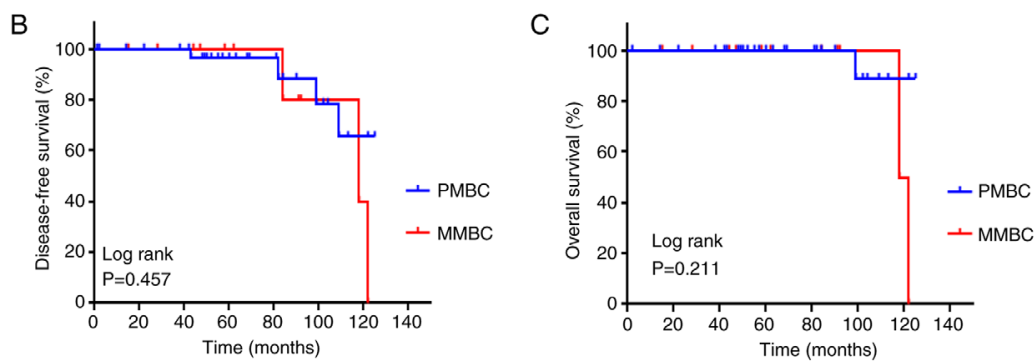

Figure 2. Treatment and prognosis of MBC. (A) Distribution of systemic treatment following surgery. The probability of (B) disease-free survival and (C) overall survival in relation to the subtypes, PMBC and MMBC. PMBC, pure mucinous breast carcinoma; MMBC, mixed mucinous breast carcinoma; CT, chemotherapy; ET, endocrine therapy; Non, no endocrine therapy and chemotherapy. 
Table VI. Prognostic significance of the clinicopathological factors on DFS and OS in patients with MBC.

\begin{tabular}{|c|c|c|c|c|c|c|}
\hline \multirow[b]{3}{*}{ Parameters } & \multicolumn{3}{|c|}{ DFS } & \multicolumn{3}{|c|}{ OS } \\
\hline & \multirow[b]{2}{*}{ P-value } & \multicolumn{2}{|c|}{$95 \% \mathrm{CI}$} & \multirow[b]{2}{*}{ P-value } & \multicolumn{2}{|c|}{$95 \% \mathrm{CI}$} \\
\hline & & Lower & Upper & & Lower & Upper \\
\hline Age (<50 vs. $>50$ years $)$ & 0.239 & 0.220 & 2.548 & 0.975 & 0.280 & 32.050 \\
\hline Tumor size (<2 vs. >2 cm) & 0.939 & N/A & N/A & 0.945 & 0.410 & 11.853 \\
\hline Nodes (positive vs. negative) & 0.986 & 0.940 & 10.256 & 0.953 & $\mathrm{~N} / \mathrm{A}$ & $\mathrm{N} / \mathrm{A}$ \\
\hline Subgroup (PMBC vs. MMBC) & 0.952 & N/A & N/A & 0.999 & N/A & N/A \\
\hline ER (positive vs. negative) & 0.980 & N/A & $\mathrm{N} / \mathrm{A}$ & 0.990 & N/A & N/A \\
\hline PR (positive vs. negative) & 0.960 & N/A & N/A & 0.969 & 0.119 & 9.419 \\
\hline HER2 (positive vs. negative) & 0.944 & N/A & N/A & 0.966 & N/A & $\mathrm{N} / \mathrm{A}$ \\
\hline Ki67 (<20 vs. $>20 \%)$ & 0.498 & 0.830 & 3.361 & 0.830 & 0.051 & 10.836 \\
\hline
\end{tabular}

ER, estrogen receptor; PR, progesterone receptor; HER2, human epidermal growth factor receptor 2; DFS, disease-free survival; OS, overall survival; N/A, not available; CI, confidence intervals; MBC, mucinous breast carcinoma.
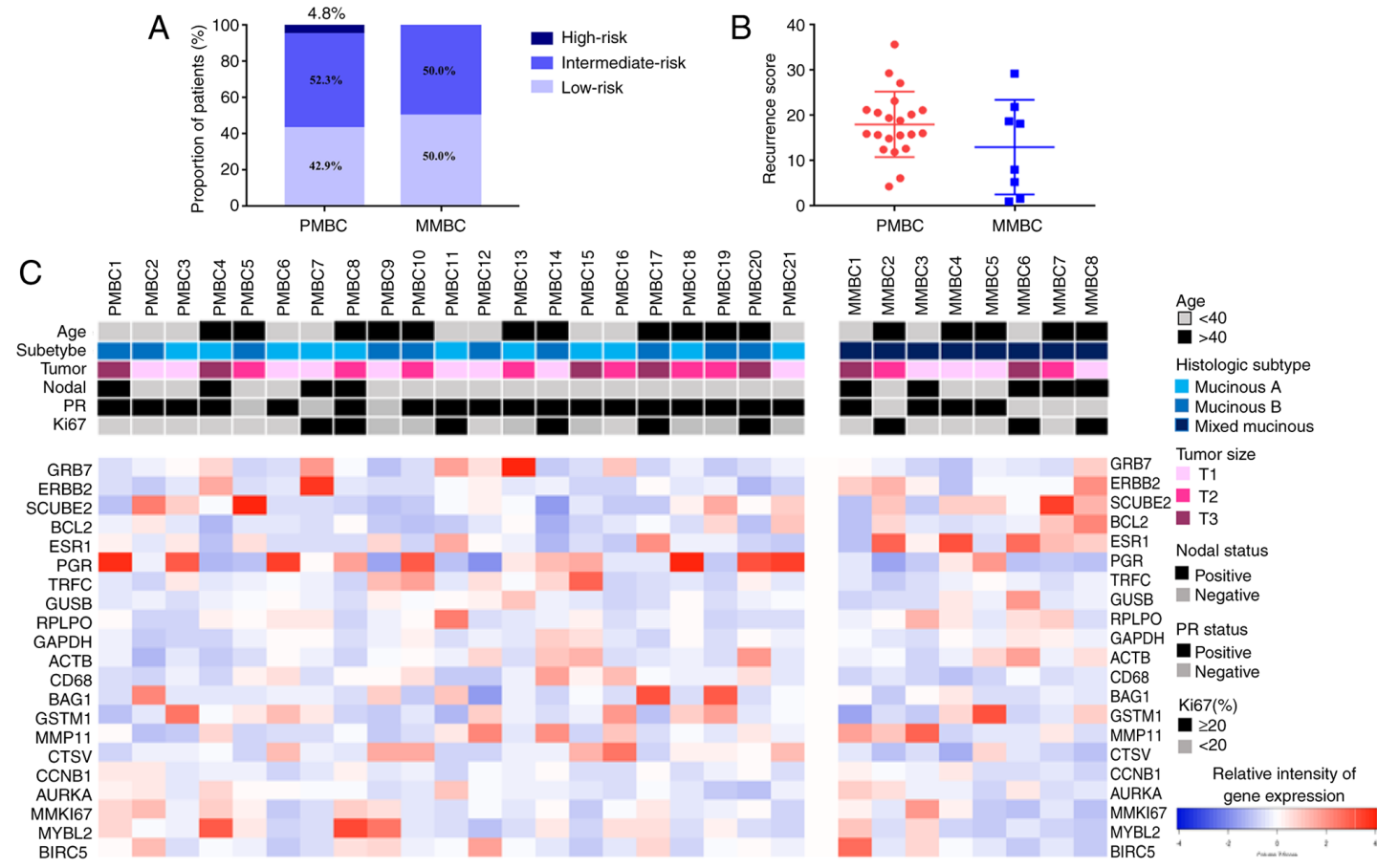

Figure 3. Expression levels of the 21-genes in mucinous breast carcinomas. (A) Proportion of the 21-gene risk stratification in PMBC and MMBC cases $(\mathrm{P}=0.91)$. (B) Distribution of the 21-gene RS in PMBCs and MMBCs ( $\mathrm{P}=0.151)$. (C) Individual expression levels of the 16 cancer genes from the 21-gene RS identified in PMBCs $(n=21$; left) and in the MMBC $(n=8$; right). Histopathological characteristics are depicted in the phenotype bars (top) and the relative intensity of gene expression is shown in the heat map. PMBC, pure mucinous breast carcinoma; MMBC, mixed mucinous breast carcinoma; RS, recurrence score; PR, progesterone receptor.

present study could avoid CT, and $27.6 \%$ of them could choose CT or not. Notably, the NSABP B-20 study reported that only patients which had a RS $\geq 31$ benefited the most from adjuvant CT (30), and the TAILORx study only recommended that patients with a $\mathrm{RS} \geq 26$ receive adjuvant CT (31). Furthermore, the Southwest Oncology Group-8814 and Eastern Cooperative Oncology Group E2197 studies extended the application of the 21-gene RS assay to the lymph node positive population, as well as advocated RS use in patients with 1-3 positive lymph nodes and considered omitting adjuvant $\mathrm{CT}$ in those with a RS <18 (12,13). However, this requires further research for confirmation. In addition, previous research has analyzed the association between RS and the prognosis of MBC and found that it is no significant differences in DFS and OS rates among MBC patients in different RS risk groups (15). However, it is difficult to analyze the association between RS and prognosis in the study as only 2 patients had metastasis (PMBC14, RS, 18.87 and PMBC2, RS, 15.63). 
Table VII. Comparison of individual gene expression levels of the 16 cancer genes from the 21-gene RS in patients with PMBC and MMBC.

A. Proliferation group

\begin{tabular}{|c|c|c|c|}
\hline Gene name & $\mathrm{AEI}$ in $\mathrm{PMBC} \pm \mathrm{SD}$ (range) & $\mathrm{AEI}$ in $\mathrm{MMBC} \pm \mathrm{SD}$ (range) & P-value \\
\hline CCNB1 & $0.93 \pm 1.17(0.5-5.58)$ & $1.26 \pm 0.41(0.41-1.53)$ & 0.793 \\
\hline AURKA & $1.23 \pm 0.76(0.44-3.9)$ & $1.0 \pm 0.59(0.41-1.98)$ & 0.649 \\
\hline MKI67 & $1.56 \pm 1.75(0.31-8.45)$ & $1.15 \pm 1.29(0.21-4.16)$ & 0.324 \\
\hline MYBL2 & $2.27 \pm 4.45(0.3-21.27)$ & $0.94 \pm 0.93(0.21-2.67)$ & 0.168 \\
\hline BIRC5 & $1.48 \pm 1.49(0.17-7.06)$ & $1.22 \pm 1.14(0.24-3.46)$ & 0.401 \\
\hline
\end{tabular}

B. Invasion group

\begin{tabular}{lcc}
\hline Gene name & AEI in PMBC \pm SD (range) & AEI in MMBC \pm SD (range) \\
\hline MMP11 & $1.2 \pm 0.98(0.28-4.07)$ & $1.82 \pm 1.66(0.47-5.38)$ \\
CTSV & $1.59 \pm 1.37(0.42-6.62)$ & $0.61 \pm 0.48(0.16-1.6)$
\end{tabular}

C. ER group

\begin{tabular}{lccc}
\hline Gene name & AEI in PMBC \pm SD (range) & AEI in MMBC \pm SD (range) & P-value \\
\hline SCUBE2 & $1.53 \pm 1.66(0.14-6.24)$ & $1.92 \pm 1.84(0.43-6.06)$ & 0.401 \\
BCL2 & $1.29 \pm 1.26(0.31-5)$ & $1.37 \pm 1.00(0.5-2.94)$ & 0.457 \\
ESR1 & $1.22 \pm 1.07(0.31-4.98)$ & $2 \pm 1.12(0.48-3.65)$ & 0.053 \\
PGR & $2.83 \pm 3.19(0.05-12.9)$ & $0.7 \pm 0.86(0.04-2.53)$ & 0.018 \\
\hline
\end{tabular}

D. HER2 group

\begin{tabular}{lcc}
\hline Gene name & AEI in PMBC \pm SD (range) & AEI in MMBC \pm SD (range) \\
\hline GRB7 & $2.04 \pm 3.12(0.35-14.5)$ & $0.91 \pm 0.51(0.43-1.86)$ \\
ERBB2 & $1.26 \pm 1.62(0.32-7.96)$ & $1.57 \pm 0.90(0.4-2.84)$
\end{tabular}

E. Independent group

\begin{tabular}{lcc}
\hline Gene name & AEI in PMBC \pm SD (range) & AEI in MMBC \pm SD (range) \\
\hline CD68 & $1.38 \pm 10.8(0.32-4.66)$ & $0.63 \pm 0.22(0.42-1.04)$ \\
BAG1 & $1.6 \pm 1.83(0.36-6.7)$ & $0.96 \pm 0.44(0.43-1.74)$ \\
GSTM1 & $1.62 \pm 1.66(0.14-5.9)$ & $1.13 \pm 1.17(0.09-3.63)$
\end{tabular}

AEI, average expression intensity; PMBC, pure mucinous breast carcinoma; MMBC, mix mucinous breast carcinoma.

Next, the current study performed a comparison of the 21-gene RS between PMBCs and MMBCs and the data revealed there was no statistically significant differences between the two groups. This result suggests that PMBCs and MMBCs may have similar 21-gene RS with the same molecular subtypes (ER $\left.{ }^{+} / \mathrm{HER} 2^{-}\right)$, but larger sample studies are required to confirm this conclusion. Analysis of the individual cancer gene expression differences from the 21-gene RS between PMBCs and MMBCs was performed, and three of these genes were differently expressed in PMBC compared with MMBC. As a key element in tumor growth and metastasis, a high expression level of CTSV was previously shown to be associated with poor prognosis in breast cancer (32). In the current study, the expression of CTSV was significantly higher in PMBCs compared with that in MMBCs, which suggested that the cell invasive ability of the former may be higher compared with that of the latter. However, this phenomenon is not consistent with the fact that the lymph node metastasis rate of patients with $\mathrm{MMBC}$ was higher compared with that in patients with $\mathrm{PMBC}$ and further studies are required 
to verify the association between CTSV and MBC. PR is the main downstream signal molecule in the ER signaling pathway (33), and PR status was defined as a predictor for RS according to previous analyses in the Plan B and NASBP B20 studies $(30,34)$. The present data revealed that the expression level of PR in the PMBC group was significantly higher compared with that in the MMBC group, which suggested that PMBC had a more favorable response to ET. CD68 is a marker of macrophages and its expression can indicate the infiltration of tumor lymphocytes (35). A previous study confirmed that a high level of CD68 protein expression was associated with poor prognosis in patients with breast cancer (36). In the current study, the expression level of CD68 was higher in the PMBC group compared with the MMBC group, which indicated that the immune status was different between the two groups, which warrants further investigation.

The current study has some limitations. First, the number of MBC cases was limited due to its relatively low incidence. Second, the study was single-centered and retrospective, which could cause selection bias. Finally, the follow-up time was relatively short and ongoing, and a longer follow-up would be of benefit for further conclusions for MBC.

In conclusion, the main purpose of the present study was to evaluate the distribution pattern and clinical value of 21-gene RS in patients with MBC. The clinicopathological data and prognosis of 38 patients with PTMC and 11 patients with MMBC were analyzed and a total of 29 ER-positive and HER2-negative patients with MBC underwent the Oncotype DX 21-gene test. The results showed patients with $\mathrm{MBC}$ had favorable prognosis, and patients with PMBC and MMBC had low- and intermediate-risk RS, which suggested that a considerable proportion of patients may be able to avoid CT; however, further research and clinical trials should be conducted to confirm the observations. There were no statistically significant differences between PMBCs and MMBCs in the 21-gene RS, but the high expression level of PR-related genes in PMBCs indicated that they may have an improved response to ET compared with MMBCs. In addition, CTSV and CD68 expression showed a significant difference between the PMBC and MMBC groups, which may indicate that they have different tumor characteristics and further studies are required to verify the association of these gene expression patterns on $\mathrm{MBC}$.

\section{Acknowledgements}

Not applicable.

\section{Funding}

The present study was supported by Zunyi Science and Technology Project [Zunshi Kehe Hz Zi (2020) grant no. 258], Guizhou Province Science Plan Program (Qian Ke He Foundation-ZK [2021] General 461), National Natural Science Foundation of China (grant no. 81860715) and Doctor Foundation of Affiliated Hospital of Zunyi Medical University (grant no. 201712).

\section{Availability of data and materials}

The datasets used and/or analyzed during the current study are available from the corresponding author on reasonable request.

\section{Authors' contributions}

RC, YW, JW and XC conceived the study. RC, YW, TL, JL, NT and GF collected and interpreted the data. JW and $\mathrm{XC}$ confirm the authenticity of the raw data. RC, YW, NT and $\mathrm{JW}$ performed the data analysis. RC and $\mathrm{YW}$ wrote the manuscript. $\mathrm{XC}$, TL and JL reviewed and edited the manuscript. RC, TL and JL acquired the funding. All authors read and approved the final manuscript.

\section{Ethics approval and consent to participate}

All procedures were performed in accordance with the ethical standards of the Ethical Committees of Affiliated Hospital of Zunyi Medical University and the Declaration of Helsinki of 1964. The present study was reviewed and approved by the Ethical Committee of Affiliated Hospital of Zunyi Medical University. All patients provided written informed consent.

\section{Patient consent for publication}

Not applicable.

\section{Competing interests}

The authors declare that they have no competing interests.

\section{References}

1. Kim HS, Yoo TK, Park WC and Chae BJ: The prognostic value of HER2 status and efficacy of anti-HER2 therapy in patients with HR-positive mucinous breast cancer: A nationwide study from the Korean Breast Cancer Society. Breast Cancer Res Treat 180: 461-470, 2020.

2. Di Saverio S, Gutierrez $\mathrm{J}$ and Avisar E: A retrospective review with long term follow up of 11,400 cases of pure mucinous breast carcinoma. Breast Cancer Res Treat 111: 541-547, 2008.

3. Bae SY, Choi MY, Cho DH, Lee JE, Nam SJ and Yang JH: Mucinous carcinoma of the breast in comparison with invasive ductal carcinoma: Clinicopathologic characteristics and prognosis. J Breast Cancer 14: 308-313, 2011.

4. Barkley CR, Ligibel JA, Wong JS, Lipsitz S, Smith BL and Golshan M: Mucinous breast carcinoma: A large contemporary series. Am J Surg 196: 549-551, 2008.

5. Cao AY, He M, Liu ZB, Di GH, Wu J, Lu JS, Liu GY, Shen ZZ and Shao ZM: Outcome of pure mucinous breast carcinoma compared to infiltrating ductal carcinoma: A population-based study from China. Ann Surg Oncol 19: 3019-3027, 2012.

6. Hanagiri T, Ono K, Baba T, So T, Yamasaki M, Nagata Y, Uramoto H, Takenoyama M and Yasumoto K: Clinicopathologic characteristics of mucinous carcinoma of the breast. Int Surg 95: 126-129, 2010.

7. Lei L, Yu X, Chen B, Chen Z and Wang X: Clinicopathological characteristics of mucinous breast cancer: A retrospective analysis of a 10-year study. PLoS One 11: e0155132, 2016.

8. Skotnicki P, Sas-Korczynska B, Strzepek L, Jakubowicz J, Blecharz P, Reinfuss M and Walasek T: Pure and mixed mucinous carcinoma of the breast: A comparison of clinical outcomes and treatment results. Breast J 22: 529-534, 2016.

9. Paik S, Shak S, Tang G, Kim C, Baker J, Cronin M, Baehner FL, Walker MG, Watson D, Park T, et al: A multigene assay to predict recurrence of tamoxifen-treated, node-negative breast cancer. $\mathrm{N}$ Engl J Med 351: 2817-2826, 2004.

10. Green N, Al-Allak A and Fowler C: Benefits of introduction of oncotype DX ${ }^{\circledR}$ testing. Ann R Coll Surg Engl 101: 55-59, 2019.

11. Sparano JA, Gray RJ, Makower DF, Pritchard KI, Albain KS, Hayes DF, Geyer CE, Dees EC, Goetz MP, Olson JA, et al: Adjuvant chemotherapy guided by a 21-gene expression assay in breast cancer. N Engl J Med 379: 111-121, 2018. 
12. Goldstein LJ,Gray R, Badve S,Childs BH, Yoshizawa C, Rowley S, Shak S, Baehner FL, Ravdin PM, Davidson NE, et al: Prognostic utility of the 21-gene assay in hormone receptor-positive operable breast cancer compared with classical clinicopathologic features. J Clin Oncol 26: 4063-4071, 2008.

13. Albain KS, Barlow WE, Shak S, Hortobagyi GN, Livingston RB, Yeh IT, Ravdin P, Bugarini R, Baehner FL, Davidson NE, et al: Prognostic and predictive value of the 21-gene recurrence score assay in postmenopausal women with node-positive, oestrogen-receptor-positive breast cancer on chemotherapy: A retrospective analysis of a randomised trial. Lancet Oncol 11: 55-65, 2010.

14. Wang W, Chen X, Lin L, Fei X, Garfield DH, Hong J, Gao W, Zhu S, Wu J, Huang O, et al: Distribution and clinical utility of the 21-gene recurrence score in pure mucinous breast cancer patients: A case-control study. J Cancer 9: 3216-3224, 2018.

15. Wu J, Ding S, Lin L, Fei X, Lin C, Andriani L, Goh C, Huang J, Hong J, Gao W, et al: Comparison of the distribution pattern of 21-gene recurrence score between mucinous breast cancer and infiltrating ductal carcinoma in Chinese population: A retrospective single-center study. Cancer Res Treat 52: 671-679, 2020.

16. Lebeau A and Denkert C: Updated WHO classification of tumors of the breast: The most important changes. Pathologe 42: 270-280, 2021 (In German).

17. Kashiwagi S, Onoda N, Asano Y, Noda S, Kawajiri H, Takashima T, Ohsawa M, Kitagawa S and Hirakawa K: Clinical significance of the sub-classification of 71 cases mucinous breast carcinoma. Springerplus 2: 481, 2013.

18. Hammond ME, Hayes DF, Dowsett M, Allred DC, Hagerty KL, Badve S, Fitzgibbons PL, Francis G, Goldstein NS, Hayes M, et al: American Society of Clinical Oncology/College of American Pathologists guideline recommendations for immunohistochemical testing of estrogen and progesterone receptors in breast cancer. J Clin Oncol 28: 2784-2795, 2010

19. Dowsett M, Nielsen TO, A'Hern R, Bartlett J, Coombes RC, Cuzick J, Ellis M, Henry NL, Hugh JC, Lively T, et al: Assessment of Ki67 in breast cancer: Recommendations from the international Ki67 in Breast Cancer working group. J Natl Cancer Inst 103: 1656-1664, 2011

20. Goldhirsch A, Winer EP, Coates AS, Gelber RD Piccart-Gebhart M, Thürlimann B and Senn HJ; Panel members: Personalizing the treatment of women with early breast cancer: Highlights of the St Gallen International Expert Consensus on the Primary Therapy of Early Breast Cancer 2013. Ann Oncol 24: 2206-2223, 2013.

21. Wolff AC, Hammond MEH, Allison KH, Harvey BE, Mangu PB, Bartlett JMS, Bilous M, Ellis IO, Fitzgibbons P, Hanna W, et al: Human epidermal growth factor receptor 2 testing in breast cancer: American society of clinical Oncology/College of American pathologists clinical practice guideline focused update. J Clin Oncol 36: 2105-2122, 2018.

22. Livak KJ and Schmittgen TD: Analysis of relative gene expression data using real-time quantitative PCR and the 2(-Delta Delta C(T)) method. Methods 25: 402-408, 2001.

23. Sparano JA, Gray RJ, Makower DF, Pritchard KI, Albain KS, Hayes DF, Geyer CE, Dees EC, Perez EA, Olson JA, et al: Prospective validation of a 21 -gene expression assay in breast cancer. N Engl J Med 373: 2005-2014, 2015.

24. Abdulrahman G, Opeyemi R and Ganiyu A: Epidemiology of breast cancer in Europe and Africa. J Cancer Epidemiol 2012: 915610, 2012.
25. Yim HE, Kim JH, Ahn MS, Jung Y, Roh J, Park SH, Kim TG, Choi JK and Kang SY: Clinicopathological and molecular analysis of 45 cases of pure mucinous breast cancer. Front Oncol 10: 558760, 2020.

26. Ranade A, Batra R, Sandhu G, Chitale RA and Balderacchi J: Clinicopathological evaluation of 100 cases of mucinous carcinoma of breast with emphasis on axillary staging and special reference to a micropapillary pattern. J Clin Pathol 63: 1043-1047, 2010

27. Erhan Y, Ciris M, Zekioglu O, Erhan Y, Kapkac M, Makay O and Ozdemir N: Do clinical and immunohistochemical findings of pure mucinous breast carcinoma differ from mixed mucinous breast carcinoma. Acta Chir Belg 109: 204-208, 2009.

28. Wang J, He ZY, Dong Y, Sun JY, Zhang WW and Wu SG: The Distribution and Outcomes of the 21-gene recurrence score in T1-T2N0 Estrogen receptor-positive breast cancer with different histologic subtypes. Front Genet 9: 638, 2018.

29. Turashvili G, Brogi E, Morrow M, Hudis C, Dickler M, Norton L and Wen HY: The 21-gene recurrence score in special histologic subtypes of breast cancer with favorable prognosis. Breast Cancer Res Treat 165: 65-76, 2017.

30. Paik S, Tang G, Shak S, Kim C, Baker J, Kim W, Cronin M, Baehner FL, Watson D, Bryant J, et al: Gene expression and benefit of chemotherapy in women with node-negative, estrogen receptor-positive breast cancer. J Clin Oncol 24: 3726-3734, 2006.

31. Sparano JA, Gray RJ, Ravdin PM, Makower DF, Pritchard KI, Albain KS, Hayes DF, Geyer CE Jr, Dees EC, Goetz MP, et al: Clinical and genomic risk to guide the use of adjuvant therapy for breast cancer. N Engl J Med 380: 2395-2405, 2019.

32. Toss M, Miligy I, Gorringe K, Mittal K, Aneja R, Ellis I, Green A and Rakha E: Prognostic significance of Cathepsin V (CTSV/CTSL2) in breast ductal carcinoma in situ. J Clin Pathol 73: 76-82, 2020.

33. Mohammed H, Russell IA, Stark R, Rueda OM, Hickey TE, Tarulli GA, Serandour AA, Serandour AA, Birrell SN, Bruna A, et al: Progesterone receptor modulates ER $\alpha$ action in breast cancer. Nature 523: 313-317, 2015.

34. Gluz O, Nitz UA, Christgen M, Kates RE, Shak S, Clemens M, Kraemer S, Aktas B, Kuemmel S, Reimer T, et al: West German study group phase III planB trial: First prospective outcome data for the 21-gene recurrence score assay and concordance of prognostic markers by central and local pathology assessment. J Clin Oncol 34: 2341-2349, 2016.

35. de Groot AF, Blok EJ, Charehbili A, Engels CC, Smit VTHBM, Dekker-Ensink NG, Putter H, Meershoek-Klein Kranenbarg E, van de Velde CJH, Liefers GJ, et al: Strong CD8+ lymphocyte infiltration in combination with expression of HLA class I is associated with better tumor control in breast cancer patients treated with neoadjuvant chemotherapy. Breast Cancer Res Treat 175: 605-615, 2019.

36. Pelekanou V, Villarroel-Espindola F, Schalper KA, Pusztai L and Rimm DL: CD68, CD163, and matrix metalloproteinase 9 (MMP-9) co-localization in breast tumor microenvironment predicts survival differently in ER-positive and -negative cancers. Breast Cancer Res 20: 154, 2018.

This work is licensed under a Creative Commons Attribution-NonCommercial-NoDerivatives 4.0 International (CC BY-NC-ND 4.0) License. 